\title{
Analysis causes of the incidence and compare social, economic, physical characteristics of informal settlements, Case Study: city of Marivan In Kurdistan Province ${ }^{1}$
}

\author{
Farzad Veisi \\ Assistant Professor, Department of Geography, Payame Noor University, PO BOX 19395 - 3697 , \\ Tehran, IRAN \\ Email: geoplan1392@gmail.com
}

Keywords: informal settlement-Marivan-migration-slum-housing.

\begin{abstract}
Informal settlements are one of the problems of urban management in developing countries. Various theories about the causes and management of these settlements have been proposed. The most important of these theories, new socialist, liberal and dependency can be noted. The theory that argues for mandatory clearing informal settlement is not logical. Empowerment approach to be interested by countries and international organizations, and successful examples of this approach, with emphasis on the internal dynamics of these communities has been experienced. This paper tries to analyze the causes of marginalization and social, economic and spatial characteristics of informal settlement of Marivan city in Kurdistan province. Research areas consist of 4 region of Marivan informal settlement (Kosar,tape Mosk, sardoshiha, Tefine) sample size based on Cochran formula is 320 samples that Randomly and in four districts have been selected. Reasons for residents that they living in such places and social, economic characteristics of marginalized communities collected and entered into SPSS software and have been analyzed. The results show that more than 50 percent of residents in informal settlement areas of the city have come to this neighborhood. The main factor in the development of these four areas is not rural migrants. The highest levels of rural migrants from the neighborhood Tefin are that only $47 \%$ of residents are immigrants. The results suggest the great differences in social, economic and physical characteristics of slums. Among neighborhoods communities tapa Mosk and Tefini in the index close to each other and compare to two other neighborhoods are poor.
\end{abstract}

\section{INTRODUCTION}

The fast growing of city in the last century caused the bulk of the population living in cities in more countries. Among the biggest challenges of the 21 st century, the rapid growth of urbanization is one example of the social challenges that are embodied in cities that include various types of unemployment, climate change; environmental degradation. At the same time, the National Development locking also on hand of cities. Potential for economic opportunities, increase energy efficiency, reduce inequality and create sustainable livelihoods for all are shown on urbanization. Development of urbanization is also clear that it is a resource for development rather than product (UN Habitat, 2012). Physical and unbalanced development of urban, have followed by undesirable economic, social and physical consequences of (Naghdi \& Sadeghi, 2006). At the beginning of the twenty-first century the world population is over six billion people, mostly and over 50 percent live in urban areas (UN Habitat, 2004). Mainly concentrated in the cities with millions population. In 2001, about 31.6 percent of the world's urban population lived in slum area. 61 per cent of slum dwellers have been living in Asia (UN Habitat, 2003). It is estimated that about one billion people live in urban informal settlements (UN habitat, 2003). In such circumstances, the cities, especially in developing countries millions of people concentrated with poverty and over a large number of the poor are pushed to the periphery of the cities where the new problems arising from local conditions.In Iran, along with growing urbanization, the spread of slums and informal settlements has been pervasive phenomenon of contemporary urbanization (Irandoost \& Sharrafi, 2007). Urbanization ratio of $31.4 \%$ in 1335 reached to 68.5 percent in 1385 (Statistical Center of Iran, 
2006). The rapid growth of urban have followed different consequences that associated with the anomalies of the facility, the economic damage, environmental degradation, failure service in urban areas and marginalized communities (Heidari Noshahr \& Nazarian, 2010). The concept of social or economic marginalization implies that people live outside system and important issue is the impact of urban land use in social and economic classification (Razavian, 2002).

Marginalization is phenomenon that has emerged during the past sixty years in Iranian cities and towns and covers households and people who live in unfavorable conditions. Marginalization in iran emerged of 20s and 30s and after 1953 coincidence with implementation of developmental plan rely on oil income and concentration on industrial plan and marginalization of agriculture this phenomenon were serious.

$40 \mathrm{~s}$ is coincided with the reduced role of agriculture in the national economy and a sharp downturn in the rural economy and rural to urban migration. This time the problem of marginalization emerged as a social and structural problem of the city. In general, two main cause of marginalization in the 40s and 50 are low-income conditions and economic and social life of urban of people in margins, and its relationship with rural to urban migration (Haji-Yousefi, 2002). In fact, marginalization was not only physical phenomenon but also arises because of macro structural factors at national and regional level.

Growing urban population was more than ability of the state organizations and NGOs to develop and provide services and facilities for the urban population and unmet need for low-income housing and shelter in formal and planned city, was cause for extend marginalization (Hadizadeh Bazaz, 2003). Kurdistan province as a province of the West was relieved of the problem of marginalization and the problems and consequences of marginalization in the province is like other provinces of the country. Marivan as one of the Kurdistan city for decades faced with a dilemma of marginalization. The problem of informal settlements at the end of the war and the economic prosperity of cross-border exchanges practices with neighboring countries and rural-urban migrants from other parts of the province and in the form of unprecedented intensified between the population censuses 1996-2006 the population of city doubled. Rapid population growth and physical growth of informal settlements in the city has been increased. This study seeks to answer the question that causes initiation of marginalization in this town, and physical characteristics, economic, social, marginalized communities and what the differences and similarities with each other?

\section{THEORETICAL FRAMEWORK}

Various theories about the causes of the formation of informal settlements mentioned that with all the differences in the three main categories, liberal, radical views and the views are socialist new classification (sarrafi \& Mohammadi, 2005). In Liberal views, marginalization is from the ravages of capitalism development that in comparison with the achievements of capitalism is negligible (piran, 1995). This view tends to provide specific procedures, minimize disorders and substandard housing in terms of spatial, physical, social, and environmental and health to these areas to eventually be integrated in the urban system. Totally in this view cause of incidence of informal settlement is compulsory and because of world system and believes informal settlement should be accepted and improved (piran, 1994). According to this view, the strong population growth and density, the main cause of poverty and underdevelopment in developing countries considered that makes successful any plan to improve the standard of living and poverty in these countries. One result of formation of such a situation is an unofficial housing area. In this view primarily stressed on the physical and socio-economic aspects of informal settlements and unbalanced economic growth pattern and features is considered. In fact, at this point in its attitude to the reason and internal factors have been examined and the role of external factors in the formation of informal settlements has received less attention (Sarrafi \& Mohammadi, 2005).

Radical views, in the 60s and 70s a group of intellectuals in Latin America were believed that reason of backwardness of developing countries (the depend countries), is the effect of current economic dominance of developed countries to know their opinion and exogenous dependent 
development pattern and the industrialization process, and as a result of urban marginalized groups. Deepening the gap between urban and rural areas, to chaos in agriculture, rural to urban migration, particularly severe metropolitan and large cities, the situation caused by the global division of labor (Haji-Yousefi, 2002). Obviously during the migration to the cities, the poor immigrant groups in cannot be absorbed by the urban economy of the city and had to live on the margins of urban economic and not able to take advantage of economic growth and industrialization.

The Political Economy of space that can be classified as radical views, he believes that the development model of dependency and dependent on exogenous and industrialization process caused by rapid urbanization and uneven economic. Along with unbalanced growth, income inequality increased and the severity of the structural imbalance resulting in the emergence of the poor in urban areas. From this perspective, the marginalization of the urban transition from rural to urban deprivation (Zali \& Pourfathollah, 2011). From the perspective of socialism and new socialist thinkers, marginalization and the emergence of marginalized groups and the urban poor in the developing countries, is due to the natural course of the conflict between labor and capital, the natural outcome of the rules governing the economy significantly, the concentration of capital accumulation, economic growth and uneven development of social conflicts (territorial conflict between landowners and landless peasants, the contrast between rural and urban life, class conflict, etc.) and thus, in the uneven development of capitalist society love, conflict and social problems such as the rise of marginalization in the big cities is inevitable (Haji-Yousefi, 2002). New socialist believes in general socio-economic inequalities and marginalization that phenomenon due to infrastructure shortcomings, social and physical marginalized communities are formed (Heidari NoshahrNazarian, 2010). It is believed that the informal settlements reproduce in cities (sarrafi \& Mohammadi, 2005).The official business owners and employees, such as military, social housing was the official policy of many countries. The policy became known as the land and services (Pourmohammadi, 2000). Empowerment policies in its approach to organizing informal settlements into three categories strategy relies on the three strategies of empowerment, institution-building and capacity-building based on a partnership approach emphasizes (Pourahmad et al, 2010). In the second half of the seventies in order to find a policy that is seeing weak domestic economy and the lack of cover collective power and usability to have the existing informal settlements empowerment strategy with the promotion or improvement of the environment was advised of the After a jump in new approaches to problem solving based on the development of the local communities in relation to macro-policy development has arisen. The nature of the empowerment strategy is based on the perspective of poverty alleviation and sustainable development of human-centric, relying on the participation of citizens and the city goes.Public participation and planning with the cooperation of the people, decentralization of government decision-making, enhance the status of women and gender equality, recognition of the most important principles of community groups and local management capacity building and empowerment approach dimensions (Zali and Pourfathollah, 2011).

\section{BACKGROUND STUDIES}

Background study of marginalization in developing countries shows after World War II and the rapid growth of this phenomenon in developing countries back. Various disciplines like geography, humanities, social sciences, economics, urban planning and architecture, studied this issue. It is in the organization. Manuel Castells explains in his book Urban Development in 1977, urbanization is growing rapidly while generating employment opportunities for the population not provide newcomers finally created the sidelines of Boston's socio-economic inequalities of the urbanization of poverty heterogeneous rural to urban poverty knows (Aqabkhshy, 2003). Zahid Zahedani in research said inequality in society and in technology is the cause of marginalization and technology depend on social relationships then the the inequality in social relations eventually leads to marginalization (Zahid zahedani, 11990). Piran in the research collection about shanty in Tehran (1989) and the primacy of urban domination (1989) and citizenship city (1998) Shirabad informal settlements in Zahedan (2002) believes that the pours are not marginalized they are economically 
exploited about culture are dominated about social they are boycott and about political they are under control and dominance. Eventually piran says marginalization is one of the problem of Third World cities this is the result of long-standing ties to the global capitalist countries, irregular migration and the growth of cities, and the irrational growth of cities(Piran, 1989,1998, 2002).

Khoobayand in a research about analysis of socio-economic factors of marginalization in the process of marginalization mentions the elements of time and place as the General Conditions and the phenomenon and the social and economic elements as specific conditions for growth of marginalization and to know and understand their effects, he concludes that the unemployment rate in the marginalization is much higher than other urban areas and one of the causes of marginalization in Isfahan. The average income in marginalized area is lower than other groups urban areas. The average rent in the marginalized area of the city are lower than in other areas and the decision-making people for living on the margins is effective by this element.

Irandoost and sarrafi in research about the marginalization of Kermanshah resulted that there are different kinds of marginal settlements and urban planning to organize settlements on the basis of the type of intervention should be different marginal (Irandoost \& Sarrafi, 2007). Sarrafi in a study as to the idea of organizing informal settlements, lack of attention to the organization of marginal settlements has more losses than trying to manage them. Among other research conducted about informal settlement Shakuie Research (1986) Husseinzade Dalir (1992); Zangiabadi and mobarky (2012) pointed out.

\section{Case study}

Marivan in Kurdistan province is one of the cities in the West Region is situated at an altitude of 1268 meters above sea level is 2011 , according to the city of 110,464 inhabitants that is the province's third-largest city in terms of population.

\section{METHODOLOGY}

The study method according to the object under study, descriptive and analytical. To collect information from the library and field method is used, first, to examine the theoretical framework and records the information has been collected by libraries and library studies, to investigate the causes of the phenomenon of the informal settlements a questionnaire was designed. The validity by providing experts and experts reviewed and approved. To calculate the reliability of the questionnaire, Cronbach's alpha was used for several sections and 84 hundredth of the average value obtained that number is acceptable. Pre-test questionnaire to be completed and final bugs have been fixed. The population of this research is the marginal neighborhoods in Marivan, of which 4 have been chosen neighborhood. Inventory number required and the sample size based on 3,000 housing units announced by the municipality of Marivan for four quarters using a sample of 320 has been set. Questionnaires in 4 regions (sardoshi, Kosar, Tfyny, tape Musk) has been officially announced by the municipal areas are randomly distributed between households have been completed by interviewers. The results of the questionnaire and SPSS software have been compiled and analyzed. The analysis is mainly based on four regions and in some cases has been total.

\section{RESULTS}

\section{Social Features}

Check marginalized social features in Marivan (4 quarters example) indicates that residents of the neighborhood were mostly migrants from other areas of the city have moved to this community in the majority of rural migrants constitute a large proportion of residents of these marginal neighborhoods. But in this neighborhood in most accepted migrant neighborhood (Tfyny s) less than $50 \%, 28 \%$ Kosar, cold less than $32 \%$ and 35\% of respondents Musk hills are rural migrants. 
Table 1. Shows the origin of the inhabitants of marginalized neighborhoods

\begin{tabular}{|c|c|c|}
\hline neighboorhoods & Outside the city - percent & Inside the city- percent \\
\hline kosar & 28 & 72 \\
\hline tefini & 49 & 51 \\
\hline sardoshi & 49 & 67 \\
\hline tape moosk & 35 & 64 \\
\hline
\end{tabular}

About the reasons for migration, migrants in order of importance in the four quarters (neighbors), economic factors, lack of education, lack of health care, immigration, relatives and acquaintances, insecurity and lack of agriculture have mentioned. The importance issue of immigration for household and individual and group immigration less emigration of $3 \%$ is included.

The literacy rate among households, and about 27 percent of caregivers in the neighborhood sardoshi, 25 per cent in the neighborhood Kosar, 17 percent and 26.5 percent of respondents in the neighborhood Tfyny Musk Hill neighborhood are illiterate is much higher than the national average this could be organized in project development and act as a negative point and also shows the extent of social exclusion. The choice to live in marginal neighborhoods in large part because of cheap land and cheap residents of these neighborhoods have chosen for other reasons, including the presence of relatives and the lack of control has been in construction.

Table 2. Reason of chosen of marginalized neighborhoods by the inhabitants

\begin{tabular}{|c|c|c|c|c|c|}
\hline \multicolumn{5}{|c|}{ Reason of chosen neighbor by inhabitant } & \multirow{2}{*}{ No reason } \\
\hline neighbores & $\begin{array}{c}\text { Lack of } \\
\text { control in } \\
\text { construction }\end{array}$ & $\begin{array}{c}\text { Presence of } \\
\text { family and } \\
\text { relatives }\end{array}$ & cheap of rent & $\begin{array}{c}\text { Cheap land } \\
\text { and house }\end{array}$ & \\
\hline kosar & 3.7 & 5.6 & 21.5 & 62.7 & 6.5 \\
\hline tfyne & $\mathbf{0}$ & 3.8 & 17 & 71.7 & 5.7 \\
\hline sardoshi & 5.5 & 14 & 7.5 & 66 & 7 \\
\hline tape mosek & 4.3 & 6.7 & 15.5 & 65.5 & 7 \\
\hline
\end{tabular}

According to respondents, the problems of the neighborhood of 67 percent of the residents are solve mainly by local elders. Kosar and sardoshi this neighborhood is mainly because more residents of the city have come to the neighborhood and the neighborhood is less rustic texture. But in other areas, mainly the role of their elders. Another consideration is that the 4 neighborhoods all within the last two decades have been formed. About 85 percent of resident's kosar and 96 percent of residents sardoshi and 68 percent of residents living in the neighborhood tape Musk are less than ten years. Tfyny neighborhood that appears to more older, 32 percent of the population older than 10 years who live in the neighborhood. 
Table 3. The duration of residence in the area under study

\begin{tabular}{|c|c|c|c|c|}
\hline neighbore & $11-15$ years & $6-10$ years & $\begin{array}{c}\text { of 5 } \\
\text { years(percent) }\end{array}$ & $\begin{array}{c}\text { More than 15 } \\
\text { year(percent) }\end{array}$ \\
\hline kosar & 1.9 & 18.7 & 79.4 & $\mathbf{0}$ \\
\hline tyfeny & 19.8 & 34 & 32.1 & $\mathbf{1 2 . 3}$ \\
\hline sardoshi & 7.5 & 27.1 & 57.9 & $\mathbf{5 . 6}$ \\
\hline tape mosk & 16.4 & 19.3 & 48 & $\mathbf{1 6}$ \\
\hline
\end{tabular}

\section{Economic features}

Check local economic characteristics show a high correlation between social and economic characteristics described above, there are features such as low levels of education and skills, as part of the immigrant population has been effective in their jobs.

Table 4. Supervisor job situation in marginalized communities (percent)

\begin{tabular}{|c|c|c|c|c|c|}
\hline neighbors & $\begin{array}{c}\text { government } \\
\text { officer }\end{array}$ & $\begin{array}{c}\text { Free small } \\
\text { business }\end{array}$ & $\begin{array}{c}\text { Construction } \\
\text { worker }\end{array}$ & unemployment & others \\
\hline kosar & 15 & 39.3 & 23.4 & 15 & 3.7 \\
\hline tyfeny & 4.7 & 49.1 & 24.5 & 13.2 & 8.5 \\
\hline sardoshi & 13.1 & 41.1 & 5.6 & 16.8 & 23.4 \\
\hline tape mosk & 6 & 46 & 22.7 & 18.3 & 7 \\
\hline
\end{tabular}

Source: author

Unemployment (15\%), with little difference in the average of the country and jobs majority of residents (43\%) are employed as part of the supervisors are seasonal construction worker and the economic downturn in half a year they are well it shows. Importantly, some of the respondents didn't not their job in the neighborhood that these are active mainly in the formal and informal borders business. The important issue is the economic situation of the poorer neighborhoods Tfyny and Musk Hill neighborhood, and this fully shows their physical condition. Some of the Kosar and sardoshi residents due to suitable physical conditions have administrative jobs. Something that should not be overlooked that about half (49.6 percent) of household supervisor without any insurance and social security due to kind of jobs that are construction worker and border informal worker and usually include jobs with the uncertain nature.

\section{Physical Features}

According to data obtained from the questionnaire, not asphalt road surface, slope and stepped up the texture of some neighborhoods, inadequate urban services, the rapid growth of marginalization and night construction, network difficult access and narrow, not design base on Map, lack of open space in settlements and neighborhoods, and lack of educational and recreational spaces of the physical problems of marginalized communities is in a range of pretty good (in the neighborhood of Kosar and sardoshi) until completely inappropriate (Tfyny and tape Musk ) is located. The old buildings Much of buildings four quarters less than 10 years old in the meantime, 73 percent of buildings in the area Kosar less than 5 years, $85 \%$ of buildings in the area sardoshi and $79 \%$ hilly area of tape Musk less than 10 years, and 56 percent of buildings More than 15 years old Tfyny neighborhood that of the three new neighborhoods and tape Musk, Kosar and sardoshi, and at the same time showing a further deterioration of its buildings Tfyny area. 
Table 5. Age of buildings (in percent)

\begin{tabular}{|c|c|c|c|c|}
\hline \multirow{2}{*}{ neighbore } & \multicolumn{5}{|c|}{ Old of buildings } \\
\cline { 2 - 5 } & $\mathbf{1 0}$ to 15years & $\mathbf{5}$ to 10years & Lees 5 years & $\begin{array}{c}\text { More than } \\
\mathbf{1 5 y e a r s}\end{array}$ \\
\hline kosar & 2.8 & 16.8 & 73.9 & $\mathbf{0}$ \\
\hline tyfini & 3.8 & 18.9 & 5.7 & $\mathbf{5 6}$ \\
\hline sardoshi & 5.6 & 31.8 & 53.3 & $\mathbf{0}$ \\
\hline tape mosk & 14.5 & 23.6 & 45.5 & $\mathbf{1 6 . 4}$ \\
\hline
\end{tabular}

Source: author

This situation requires more attention, especially if the materials used in buildings in the area is measured that 80 percent of homes tape Musk and 76 percent of homes in the neighborhood Tfyny made of combined materials (durable and non-durable) this amount for Kosar 55 percent and 44 percent in sardoshi, the situation show better than in the two districts (compare to tyfini and tape musk).

The number of classes in the two neighborhoods Kosar and sardoshi, respectively, 51.4 and 86 percent of the buildings are two stories that show the suitability of the economic conditions of the inhabitants of the two neighborhoods, but in Tfyny 76 percent and 73 percent of the buildings in the neighborhood tape Musk are one class that reflects the conditions in the two areas than other areas. The number of rooms, two neighborhoods with 78.5 percent in sardoshi and 65.4 percent Kosar with two rooms, better than Tfyny region with $43.4 \%$ and 39 tape Musk.

Table 6. Average of housing unit's size

\begin{tabular}{|c|c|c|c|c|c|}
\hline \multirow{2}{*}{ neighbore } & \multicolumn{5}{|c|}{ Size of house(meter) } \\
\cline { 2 - 6 } & $\begin{array}{c}\text { More } \\
\text { than150 }\end{array}$ & $120-150$ & $100-120$ & $80-100$ & $\begin{array}{c}\text { Less } \\
\text { than80 }\end{array}$ \\
\hline kosar & 1.9 & 5.6 & 27.1 & 43 & 16.8 \\
\hline tyfini & 1.9 & 1.9 & 1.9 & 55.7 & 36.8 \\
\hline sardoshi & 4.7 & 38.3 & 16.8 & 30.8 & 7.5 \\
\hline Tape mosk & 1.9 & 3 & 7 & 53.8 & 34.2 \\
\hline
\end{tabular}

Source: author

The average size of the homes in four neighborhoods there are differences. highest average in the neighborhood Kosar to a maximum of 80 meters $(41 \%)$ and in the sardoshi on the average more about Area 80 and $100(45.8 \%)$ at the Tfyny and tape Musk area average residential units from 80 to 100 meters (52.8\% tyfini and 47.5 on the tape Musk). It also should be noted that two Kosar and sardoshi More related to the area of 100 to 120 and 120 to 150 meters, but in the area tapeMusk and Tfyny Most average of less than 80 meters and from 80 to 100 meters that represents a more disadvantaged the area. 
Table 7. The type of housing units structure

\begin{tabular}{|c|c|c|c|}
\hline \multirow{2}{*}{ neighbore } & \multicolumn{3}{|c|}{ Structure of housing unit(meter) } \\
\hline & $\begin{array}{l}\text { Concret } \\
\text { structure }\end{array}$ & Metal structure & Without structure \\
\hline kosar & 0 & 94.4 & 3.7 \\
\hline tyfini & 5.7 & 40.6 & 53.7 \\
\hline sardoshi & 3.7 & 85.0 & 11.2 \\
\hline Tape musk & 6.3 & 45.4 & 43.5 \\
\hline
\end{tabular}

Source: author

The structure of residential units in the area of tape Musk and Tfyny majorly without structure in two areas that represent the poor stability and security area houses at the time of the earthquake. Also it shows the poor economic situation of residents, but in sardoshi regions and Kosar it appears better situation because more than 85 percent of homes are with the skeleton.

The readiness to contribute to the development and local problems Tfyny with 90.6 percent, tape Musk with 84.4 percent, Kosar with 74.8 percent and sardoshi 79.4 percent agreed to participate. important issue that must be addressed is that the two areas are located on the slope of tape Musk and Tfyny and the price of land in the lower compare to the two regions and sardoshi and Kosar and sardoshi are the two neighborhoods in areas with low slope and are suitable for construction.

\section{CONCLUSION}

Data from the research and analysis conducted shows that most residents of other neighborhoods in the city of Marivan marginalized communities have come to these areas and the rural migrants are not marginalized areas of the major causative agent

However, this does not mean the presence of rural migrants in marginalized neighborhoods, but in terms of population with a smaller percentage than other groups. The findings differ from the results of research the source of the phenomenon of rural migrants are marginalized. The results of the findings and analyzes carried out show that a large difference in the index of social, economic and physical, between the communities are marginalized. In this study, a total condition of two neighborhoods Kosar and sardoshi are vary and better neighborhood of Tfyny and tape Musk. In fact, with marginalization definitions or indicators two neighbore Kosar and sardoshi except on the streets width and compliance with building and construction permits for the settlements in other cases, such as the lack of infrastructure, average size of house land, the number of class, type of structure and materials, and the infrastructure and number of rooms per household, the local situation is not comparable to marginalized communities, in fact, we are faced with neighborhoods that are characteristics of the physical, social and economic between marginalized communities and Official tissue located in various studies that the appropriate conditions are marginalized neighborhoods as settlements with hope and despair settlements called the front point (Irandoost \& sarrafi, 2007).

These neighborhoods on the opinions and Stokes (Irandoost \& sarrafi, 2007) are analyzed together with the difference that Stuxnet studies Settlements hope over time that is formed over time, some residents of other settlements in accordance with marginal settlements are better off while in the present study settlements with these conditions have been better than the first time the 
same conditions as the other settlements in the present situation not been reached. It seems that according to the characteristics, the areas between formal and informal contexts are so named because they can be semi-official organs that have the characteristics of both the formal and informal contexts.

${ }^{1}$ This project sponsored by PNU Kurdistan province and in particular credit (Grant) has been performed.

\section{References}

[1] Aqabkhshy, S. (2003). Marginalization and informal settlements, University of Social Welfare and Rehabilitation Sciences, 2: 195-210.

[2] Naghdi, A., \& Sadeghi, R. (2006). Marginalization challenge for sustainable urban development (with emphasis on the Hamadan), Journal of Social Welfare, 5(10): 215-227.

[3] Razavian, M. T. (2002). Urban land use planning. Tehran: Monshi publication.

[4] Haji-Yousefi, A. (2002). Urban margins and the evolution it (before the Islamic Revolution) haft shahr, 8: 12-24.

[5] Statistical Center of Iran. (2006). General Population and Housing Census, the city of Marivan Detailed results.

[6] Hadizadeh bazaz, M. (2003). Margins and the the way proposed to restructuring of marginalization in the world, printing, municipal with partners Tyhv.

[7] Pour-Mohammadi, M. (2000). House planning, first printing, Tehran: samt publication.

[8] Pourahmad, A., Rahnamaiy, M. T., Gharakhlou, M., \& Eskandari nodeh, M. (2010). Pathology of government policy on organizing informal settlements, Case Study: Neighborhood nayband, shir sevom, khaje sara, Bandar Abbas

[9] Zali, N., \& Pourfathollah, J. (2011). analysis of the economic, social of marginalized neighborhoods of the city of Ahar, Urban and Regional Planning Research and Studies, 15(2): 91-105.

[10] Sarrafi, M., \& Mohammadi, A. (2005). The formation and expansion of informal settlements, causes, challenges and strategies, case study: Trans neighborhood in the city of zanjan. Journal of Earth Sciences, 11: 59-79.

[11] Heidari Noshahr, M., \& Nazarian, A. (2010). Factors affecting marginalized and its repercussions, with emphasis on the use of municipal services, the city of Yazd. Quarterly geographical territory, 31: 32- 45.

[12] Zahedani Zahid, S. (1990). Marginalization, Shiraz: Shiraz University publication.

[13] Piran, P. (1994). The city citizen,. economic and political information, August and September, the number 131132.

[14] Piran, P. (2002). Still in the informal settlements, case study: Shirabad Zahedan, Journal of haft Cities, 3: ,7-24.

[15] Piran, P. (1989). Shanty in Tehran, political-economic information, 6: 125- 140.

[16] Shakuie, H. (1986). The marginalized in Tabriz, Urban Research Institute, University of Tabriz.

[17] Hosseinzade dalir, K. (1992). marginalization: in search of meaning, political, economic information, No. 45-46 
[18] Zangi Abadi, A., Mubarak, O. (2012). The effective factors on the formation of marginalization of Tabriz and its consequences, the case study (neighborhood Ahmadabad, Paradise Alley, Khalil Abad) Journal of Geography and Environmental Planning, University of Isfahan, 23 (1 (45): 67-80.

[19] Irandoost, K., \& Sarrafi, M. (2007). Despair and hope in informal settlements, case study: the city of Kermanshah. Journal of Social Welfare, 26(7): 201-221.

[20] Habitat, U. (2003). The challenge of slums; global report on human settlements

[21] Habitat, U. (2012). Urban planning for leaders, UN habitat for a better urban future.

[22] Habitat, U. (2004). State of world's cities: trends in sub-Saharan Africa urbanization and metropolitanisation. Available at http://www.unhabitat.org. 